\title{
Prevalence of soil-transmitted helminth infections and associated risk factors among elderly individuals living in rural areas of southern Thailand
}

\author{
Ratee Kache ${ }^{1}$, Nonthapan Phasuk ${ }^{1,2}$, Parnpen Viriyavejakul ${ }^{3}$ and Chuchard Punsawad $^{1,2^{*}}$ (D)
}

\begin{abstract}
Background: Soil-transmitted helminth (STH) infection is a neglected tropical disease affecting approximately 1.5 billion people worldwide. In past decades, most studies focused on STH infection in preschool-aged and schoolaged children in different regions of Thailand. However, little is known about the prevalence and intensity of STH infection in the elderly population. Therefore, the aim of this study was to determine the current prevalence and intensity of STH infections and to identify associated risk factors among the elderly population.

Methods: A cross-sectional study was conducted from July to November 2019 to assess the prevalence of STH infections and associated risk factors among elderly populations living in five subdistricts of Thasala District, Nakhon Si Thammarat Province, Thailand. A total of 439 elderly individuals were selected using a random sampling technique. Each fresh stool sample was examined using the formalin ethyl acetate concentration technique (FECT), Kato-Katz thick smears and agar plate culture (APC). A structured questionnaire was used to obtain relevant information regarding associated risk factors for STH infection.

Results: The overall prevalence of STH infection was 15.7\%. Hookworms (10.9\%, 48/439) were the most prevalent STH species, followed by Strongyloides stercoralis (3.4\%, 15/439) and Trichuris trichiura (2.1\%, 9/439). Most elderly individuals infected with hookworms or T. trichiura had light-intensity infections. A higher prevalence of STH infection was observed among individuals aged older than 80 years (23.4\%) than among those aged between 70 and 79 years (15.2\%) and 60-69 years (14.5\%). Males were 1.85-times more likely to present with STH infections than females. Not washing vegetables before eating increased the risk of STH infection by 3.19 times, while defecation in an open field increased the risk of STH infection by 2.65 times.

Conclusions: The findings suggested that STH infection is prevalent, and that hookworms are the most common STH species among elderly populations in southern Thailand. Personal hygiene and deworming programs should be implemented among the elderly population to reduce the risk and prevent the spread of STH infections.
\end{abstract}

Keywords: Soil-transmitted helminth infections, Tha Sala District, Prevalence, Risk factor, Elderly

\footnotetext{
* Correspondence: chuchard.pu@wu.ac.th

${ }^{1}$ School of Medicine, Walailak University, Nakhon Si Thammarat, Thailand

${ }^{2}$ Tropical Medicine Research Unit, Research Institute for Health Sciences,

Walailak University, Nakhon Si Thammarat 80160, Thailand

Full list of author information is available at the end of the article
}

(c) The Author(s). 2020 Open Access This article is licensed under a Creative Commons Attribution 4.0 International License, which permits use, sharing, adaptation, distribution and reproduction in any medium or format, as long as you give appropriate credit to the original author(s) and the source, provide a link to the Creative Commons licence, and indicate if changes were made. The images or other third party material in this article are included in the article's Creative Commons licence, unless indicated otherwise in a credit line to the material. If material is not included in the article's Creative Commons licence and your intended use is not permitted by statutory regulation or exceeds the permitted use, you will need to obtain permission directly from the copyright holder. To view a copy of this licence, visit http://creativecommons.org/licenses/by/4.0/ The Creative Commons Public Domain Dedication waiver (http://creativecommons.org/publicdomain/zero/1.0/) applies to the data made available in this article, unless otherwise stated in a credit line to the data. 


\section{Background}

Soil-transmitted helminth (STH) infections are considered a neglected tropical disease and include three main species of parasites: Ascaris lumbricoides (roundworm), Trichuris trichiura (whipworm) and Ancylostoma duodenale and Necator americanus (hookworms) [1-3]. The World Health Organization (WHO) estimated that more than 1.5 billion people are infected with STHs worldwide, and infection is widely distributed in tropical and subtropical areas [4]. Southeast Asia has been reported to have the highest prevalence of STH infection $[5,6]$. Regarding age distributions and prevalence, ascariasis and trichuriasis mainly affect children, whereas hookworm affects both children and adults [1, 6]. Morbidity and mortality due to $\mathrm{STH}$ infections are related to the intensity of the infection in an affected person, as well as age and immunity [5]. In addition, several factors are related to the high prevalence of STH infections in tropical and subtropical countries, including climatic conditions, poor sanitation, a lack of safe water and poor hygiene practices $[1,7]$.

In Thailand, intestinal parasitic infections are prevalent in all regions; however, STH infections, especially hookworm infections, are particularly prevalent in the southern region of Thailand [8-11]. The prevalence of hookworm infection in both the Philippines and Thailand increases in the 20-29-year-old age group and remains high across all older age groups [6]. The prevalence rates of parasitic infections among children in neighboring countries were as high as $69.7 \%$ in Myanmar [12] and $98.4 \%$ in Malaysia [13]. In southern Thailand, hookworms are most common (15.8\%), followed by T. trichiura (3.9\%) and A. lumbricoides $(1.7 \%)$, and the highest infection intensities are found in adults [8]. Recently, a prevalence survey of intestinal parasite infections conducted by village health volunteers in rural communities in southern Thailand revealed that people aged older than 40 years had a higher prevalence of helminth infection than those aged younger than 40 years [10], which was consistent with the result of a systematic review focusing on STH infection in Southeast Asia; the review demonstrated a high prevalence of hookworm infection in older age groups [6]. However, no studies have focused on STH infection in the elderly population in southern Thailand.

The number of older people in Thailand has increased since 1990 and is expected to increase through 2040, and population growth estimates range from 696.6 to $769.8 \%$ in 2020 and 2040, respectively [14]. Previous studies indicated that elderly individuals were infected with intestinal parasites at rates of 16.2 and $17.7 \%$ in Surin Province, northeastern Thailand and Chachoengsao Province, central Thailand, respectively $[15,16]$. Furthermore, the rate of hookworm infections was $5.7 \%$ in Songkhla Province, southern Thailand [17]. Currently,
Nakhon Si Thammarat, a province in southern Thailand, has an aging society. Considering the rapid increase in the aging population, this study aimed to investigate the prevalence and risk factors of STH infections in elderly people in Tha Sala District, Nakhon Si Thammarat Province, Thailand. Knowledge of the distribution and extent of STH infections is a prerequisite for planning and evaluating intervention programs.

\section{Methods}

\section{Study design and setting}

This cross-sectional study was conducted over a fourmonth period from July to November 2019 in Tha Sala District, Nakhon Si Thammarat Province, Thailand. Tha Sala District is located at $8^{\circ} 40^{\prime} 0^{\prime \prime} \mathrm{N}$ latitude and $99^{\circ} 55^{\prime}$ 54 "E longitude and has a total area of $363.891 \mathrm{~km}^{2}$; it is approximately $750 \mathrm{~km}$ from Bangkok, the capital city of Thailand. The average temperature in southern Thailand is $27.7^{\circ} \mathrm{C}$, with a minimum of $27^{\circ} \mathrm{C}$ in January and a maximum of $28.5^{\circ} \mathrm{C}$ in May. The annual rainfall is $1959.2 \mathrm{~mm}$ (Climatological Center, Thai Meteorological Department, Annual Report 2018). Tha Sala District is divided into 10 subdistricts, which are further subdivided into 110 administrative villages, and the total population was 113,323 in 2019 (The Official Statistics Registration System, Thailand Department of Provincial Administration). Most land is used for farming, followed by rubber plantations and fishing.

\section{Study population and sample size}

The target study population was elderly people living in five subdistricts of Thasala District: Thai Buri, Tha Sala, Hua Tapan, Mokhalan, and Pho Thong (Fig. 1). The number of elderly individuals (aged 60 years and older) at the time was 16,968 . The sample size was determined by the statistical formula $n=\mathrm{N} / 1+\mathrm{Ne}^{2}$ [18], where $\mathrm{N}$ is the size of the elderly population in Tha Sala District, and $e$ is the error tolerance level of 0.05 at the $95 \%$ confidence level. The calculated sample size was 391. To minimize errors caused by exclusion due to incomplete data or inadequate stool samples, the sample size was increased by $10 \%$. The final sample size of this study was 430 individuals. The actual sample numbers of elderly participants from each subdistrict were determined by a random sampling technique.

\section{Questionnaire survey}

A structured questionnaire was prepared to gather relevant information from each participant. Two domains were addressed in the questionnaire: sociodemographic (i.e., age, sex, monthly family income and education level) and risk factors for STH infections (i.e., handwashing before meals, eating fresh vegetables and wearing shoes). The content validity of the questionnaire was assessed by 


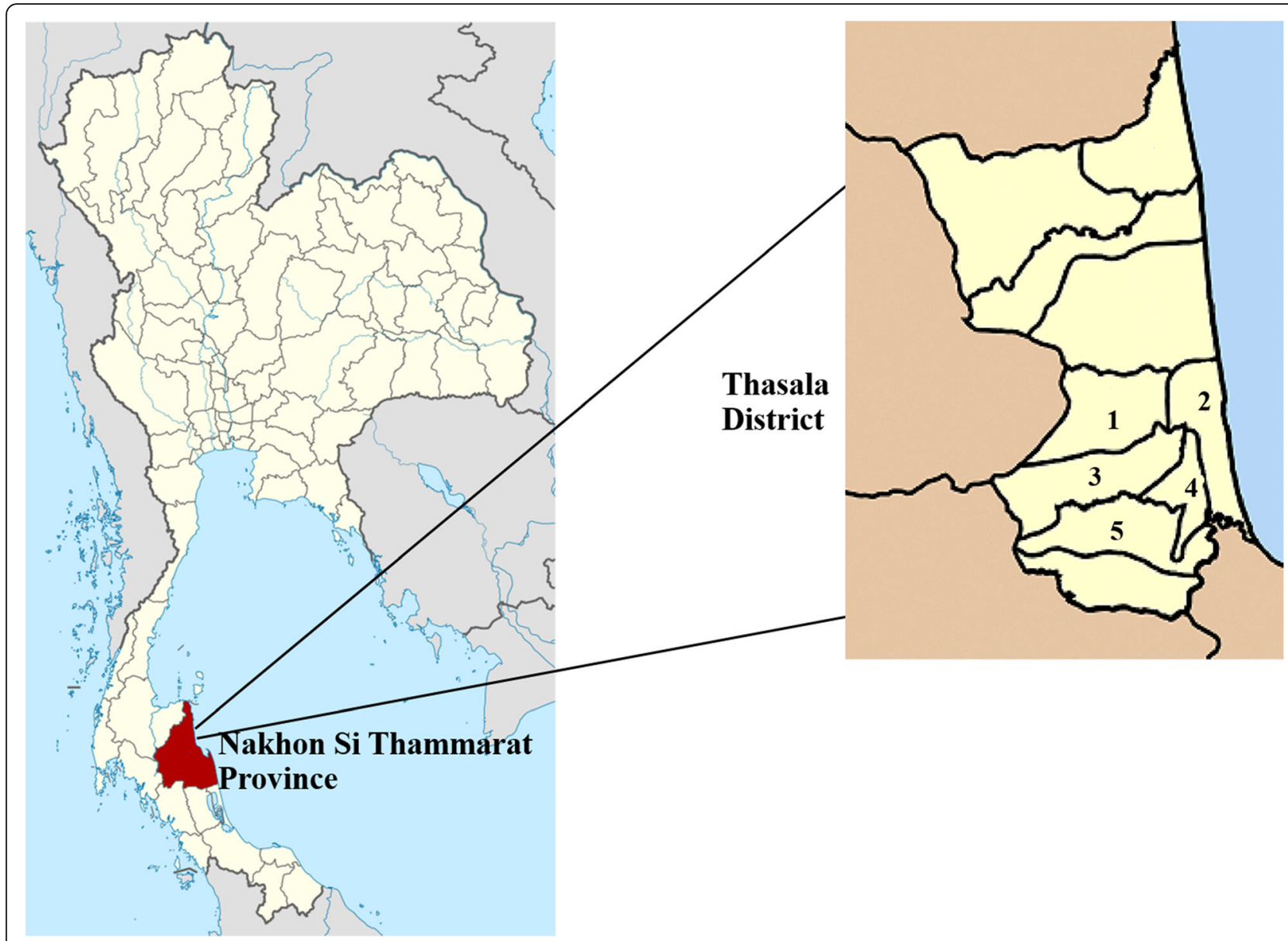

Fig. 1 Map of Tha Sala District, Nakhon Si Thammarat Province, southern Thailand. Thai Buri (1), Tha Sala (2), Hua Taphan (3), Pho Thong (4) and Mokkhalan (5). (Map from https://commons.m.wikimedia.org/wiki/Atlas_of_Thailand)

three experts in the field of parasitology or related fields. The reliability of the questionnaire was pretested with thirty individuals in a nonstudy sample population who lived outside the study area, and Cronbach's alpha coefficient for the questionnaire was calculated to be 0.827 .

\section{Stool sample collection and parasitological examination}

All participants were given a stool container labeled with an identification number and asked to submit a fresh stool sample of approximately $10 \mathrm{~g}$ the next day. Each stool sample was assessed for correct labeling and an adequate sample quantity and transferred immediately to the parasitology laboratory of Walailak University. For parasitological analysis, each stool sample was examined for STH parasites by the formalin ethyl acetate concentration technique (FECT) to detect the eggs and larvae of helminths and Kato-Katz thick smears to quantify the number of helminth eggs excreted in stool (expressed as eggs per gram, EPG) following WHO and Centers for Disease Control standard operating procedures [19]. The intensity of STH infection was classified into three categories, namely, light, moderate or heavy intensity, according to $\mathrm{WHO}$ recommendations [20]. Additionally, the agar plate culture (APC) technique [21] was used to detect the presence of $S$. stercoralis in each specimen. In brief, two grams of fresh stool sample was placed on the center of nutrient agar plates and incubated for 3-5 days at room temperature [21]. The surface of the agar plate was examined under a stereomicroscope on the third or fifth day for the presence of either rhabditiform or filariform larvae. Each sample was prepared and examined in duplicate. All parasitological examinations were performed by an experienced medical technologist who was blinded to the information of the participants. For examination quality control, $10 \%$ of the stool samples were re-examined by another experienced parasitologist.

\section{Data analysis}

The data were entered into an Excel database and double-checked to validate all data before analytical processing. All data analyses were performed using IBM SPSS Statistics for Windows, Version 23.0 (SPSS, Chicago, IL, 
USA). The elderly individuals were classified into 3 age groups: $60-70$ years, $70-80$ years and older than 80 years. Means and standard deviations (SD) were used to describe the quantitative factors, while frequency (\%) was used to describe the qualitative factors. Proportions with $95 \%$ confidence intervals (CIs) were used to describe the prevalence of intestinal parasites. Initially, the chisquare test was used to assess differences in the presence of intestinal parasites by age group and subdistrict. Univariable analysis was utilized to examine the crude odds ratio (COR) of the binary outcome variable for each independent variable. All variables with $P$-values less than 0.2 in the univariable analysis were subjected to multivariable analysis to adjust for possible confounders. The final analysis was interpreted as adjusted odds ratios (AORs) with 95\% CIs. P-values less than 0.05 were considered statistically significant.

\section{Results}

Sociodemographic characteristics

A total of 439 elderly individuals comprising 295 females (67.2\%) and 144 males participated in the study. The mean age of the participants was 69.7 (standard deviation 7.2) years. Most (241/439) of the elderly individuals were between the ages of 60 and 70 years. More than half $(74.26 \%)$ of the participants were Buddhists. Almost all $(91.8 \%)$ of the study participants had an elementary-level education. Most of the participants' occupations were agriculturists. The average monthly household income of most of the participants was less than 10,000-20,000 baht (Table 1).

\section{Prevalence of STH infections}

Of the 439 individuals who were examined for STH infection, the overall prevalence of STH infections among

Table 1 Sociodemographic characteristics of the elderly participants in Tha Sala District, Nakhon Si Thammarat Province, southern Thailand $(n=439)$

\begin{tabular}{|c|c|c|c|}
\hline Characteristics & & Number & Percentage \\
\hline \multirow[t]{2}{*}{ Sex } & Male & 144 & 32.80 \\
\hline & Female & 295 & 67.20 \\
\hline \multirow[t]{3}{*}{ Age group } & 60-69 years & 241 & 54.90 \\
\hline & 70-79 years & 151 & 34.40 \\
\hline & $>80$ years & 47 & 10.71 \\
\hline \multirow[t]{5}{*}{ Subdistrict } & Tha Sala & 90 & 20.50 \\
\hline & Hua Taphan & 89 & 20.27 \\
\hline & Moklan & 85 & 19.36 \\
\hline & Pho Thong & 87 & 19.82 \\
\hline & Thai Buri & 88 & 20.05 \\
\hline \multirow[t]{2}{*}{ Religion } & Buddhism & 326 & 74.26 \\
\hline & Islam & 113 & 25.74 \\
\hline \multirow[t]{3}{*}{ Marital status } & Single & 25 & 5.69 \\
\hline & Married/Couple & 289 & 65.83 \\
\hline & Widowed/Divorced & 125 & 28.47 \\
\hline \multirow[t]{3}{*}{ Education } & Elementary education & 403 & 91.80 \\
\hline & Secondary education & 17 & 3.87 \\
\hline & Higher education & 19 & 4.43 \\
\hline \multirow[t]{6}{*}{ Occupation } & Agriculturist & 187 & 42.60 \\
\hline & Hireling & 46 & 10.48 \\
\hline & Retired government official & 8 & 1.82 \\
\hline & Merchant/Private business worker & 29 & 6.61 \\
\hline & Housekeeper/Housewife/Househusband & 83 & 18.91 \\
\hline & Unemployed & 86 & 19.59 \\
\hline Monthly household & Less than 10,000 baht & 256 & 58.31 \\
\hline \multirow[t]{3}{*}{ Income (Thai baht) } & $10,001-20,000$ & 140 & 31.89 \\
\hline & $20,001-30,000$ & 33 & 7.52 \\
\hline & Greater than 30,001 & 10 & 2.28 \\
\hline
\end{tabular}


elderly participants was $15.7 \%$ (69/439). Most of the positive individuals had a single infection $(92.8 \%, 64 / 69)$, whereas five participants $(7.2 \%, 5 / 69)$ had multiple infections, including five cases of hookworm and T. trichiura coinfection and only one case of hookworm and Enterobius vermicularis coinfection. The most prevalent STHs were hookworms at 10.9\% (48/439), followed by Strongyloides stercoralis at $3.4 \%(15 / 439)$ and $T$. trichiura at $2.1 \%$ (9/439) (Table 2). A. lumbricoides was not detected in any of the specimens examined. In addition, E. vermicularis was found in one of 439 participants. A higher prevalence of STH infection was observed in the elderly population aged more than 80 years $(23.4 \%)$ than in the populations aged $70-79$ years $(15.2 \%)$ and 60-69 years (14.5\%). According to the sex of the participants, male participants had an overall prevalence of $20.8 \%$ (30/114), whereas the infection rate among female participants was $13.2 \%(39 / 256)$, and a significant difference in infection rates was found between male and female participants $\left(X^{2}=4.23, P=0.04\right)$ (Table 2 ).

Regarding the intensity of STH infection, the mean numbers of EPG in stool were 143.88 EPG (SD: 339.39) and 63.95 EPG (SD: 46.44) for hookworm and T. trichiura, respectively. Of the 48 elderly individuals who were positive for hookworm infection, most had light-intensity hookworm infections $(97.9 \%, 47 / 48)$, and only one had a moderate-intensity infection. All elderly individuals infected with $T$. trichiura had low-intensity infections.
The prevalence of STH infections ranged from 4.4 to $28.2 \%$ according to study sites. The highest prevalence of STH infections was observed in the Moklan subdistrict $(28.2 \%)$, followed by the Thai Buri (17.0\%), Pho Thong (16.1\%), Hua Taphan (13.5\%) and Tha Sala (4.4\%) subdistricts. A significant difference in the infection rate was observed among the study sites $\left(X^{2}=\right.$ 19.15, $P=0.001$ ) (Table 2).

\section{Potential risk factors for STH infection in elderly individuals}

The results of the univariable and multivariable analyses of the risk factors associated with STH infections are shown in Table 3. Univariable analysis revealed that males were 1.72-times more likely to have STH infections than females $(\mathrm{AOR}=1.72 ; 95 \% \mathrm{CI} 1.02-2.92)$. A significant association was also identified between STH infections and washing vegetables before eating (COR 3.16; 95\% CI: 1.73-5.76). No significant associations were found between STH infection and age group, occupation or monthly family income $(P>0.05)$ (Table 3$)$. The multivariable analysis also showed that sex, washing vegetables before eating and defecation in a pit toilet or on the soil in a garden were significantly associated with $\mathrm{STH}$ infections. Males were 1.85 times more likely to develop STH infections than females $(\mathrm{AOR}=1.85 ; 95 \% \mathrm{CI}$ 1.07-3.19). Elderly people who did not regularly practice vegetable washing were 3.19 times more likely to have

Table 2 Prevalence of soil-transmitted helminth (STH) infections stratified by sex, age group and subdistrict

\begin{tabular}{|c|c|c|c|c|c|}
\hline & & \multicolumn{4}{|l|}{ STH species } \\
\hline & & Hookworms n (\%) & $\begin{array}{l}\text { Strongyloides } \\
\text { stercoralis n (\%) }\end{array}$ & $\begin{array}{l}\text { Trichuris } \\
\text { trichiura n (\%) }\end{array}$ & Total n (\%) \\
\hline \multirow[t]{5}{*}{ Sex } & Male $(n=144)$ & $20(13.9)$ & $8(5.6)$ & $3(2.1)$ & $30(20.8)$ \\
\hline & Female $(n=295)$ & $28(9.5)$ & $7(2.4)$ & $6(2.0)$ & $39(13.2)$ \\
\hline & Overall $(n=439)$ & $48(10.9)$ & $15(3.4)$ & $9(2.1)$ & $69(15.7)$ \\
\hline & $x^{2}$ & 1.921 & 2.97 & 0.001 & 4.234 \\
\hline & $P$-value & 0.166 & 0.085 & 0.973 & $0.040^{*}$ \\
\hline \multirow[t]{5}{*}{ Age group (years) } & $60-69(n=241)$ & $22(9.1)$ & $9(3.7)$ & $4(1.7)$ & $35(14.5)$ \\
\hline & $70-79(n=151)$ & $17(11.3)$ & $5(3.3)$ & $3(2.0)$ & $23(15.2)$ \\
\hline & $>80(n=47)$ & $9(19.1)$ & $1(2.1)$ & $2(4.3)$ & $11(23.4)$ \\
\hline & $x^{2}$ & 4.08 & 0.315 & 1.324 & 2.383 \\
\hline & $P$-value & 0.130 & 0.854 & 0.516 & 0.304 \\
\hline \multirow[t]{7}{*}{ Study site } & Tha Sala $(n=90)$ & $2(2.2)$ & $2(2.2)$ & $0(0.0)$ & $4(4.4)$ \\
\hline & Hua Taphan $(n=89)$ & $8(9.0)$ & $3(3.4)$ & $2(2.2)$ & $12(13.5)$ \\
\hline & Moklan $(n=85)$ & $16(18.8)$ & $5(5.9)$ & $4(4.7)$ & $24(28.2)$ \\
\hline & Pho Thong $(n=87)$ & $11(12.6)$ & $2(2.3)$ & $2(2.3)$ & $14(16.1)$ \\
\hline & Thai Buri $(n=88)$ & $11(12.5)$ & $3(3.4)$ & $1(1.1)$ & $15(17.0)$ \\
\hline & $x^{2}$ & 13.275 & 2.285 & 5.279 & 19.15 \\
\hline & $P$-value & $0.010^{*}$ & 0.684 & 0.260 & 0.399 \\
\hline
\end{tabular}


Table 3 Univariable and multivariable analyses of risk factors associated with soil-transmitted helminth (STH) infections in the participants

\begin{tabular}{|c|c|c|c|c|c|c|c|}
\hline Variables & Positive No. (\%) & Negative No. (\%) & Total $n=439$ & COR $(95 \% \mathrm{Cl})$ & $P$-value & AOR $(95 \% \mathrm{Cl})$ & $P$-value \\
\hline \multicolumn{8}{|l|}{ Sex } \\
\hline Male & $30(20.8)$ & $114(79.2)$ & $144(32.8)$ & $1.72(1.02-2.92)$ & $0.041^{*}$ & $1.85(1.07-3.19)$ & $0.027^{*}$ \\
\hline Female & $9(13.2)$ & $56(86.8)$ & $295(67.2)$ & & & & \\
\hline \multicolumn{8}{|l|}{ Age in years } \\
\hline $60-69$ & $35(14.5)$ & $206(85.5)$ & $241(54.9)$ & & & & \\
\hline 70-79 & $23(15.2)$ & $128(84.8)$ & $151(34.4)$ & $0.56(0.26-1.19)$ & 0.132 & $1.05(0.58-1.90)$ & 0.881 \\
\hline$>80$ & $11(23.4)$ & $36(76.6)$ & $47(10.7)$ & $0.59(0.26-1.32)$ & 0.198 & $2.01(0.91-4.46)$ & 0.885 \\
\hline \multicolumn{8}{|c|}{ Monthly family income (Thai baht) } \\
\hline$<10,000$ & $35(13.7)$ & $155(82.9)$ & $256(57.3)$ & $0.69(0.41-1.16)$ & 0.165 & $0.83(0.05-1.44)$ & 0.511 \\
\hline$\geq 10,001$ & $34(18.6)$ & $215(85.3)$ & $183(41.7)$ & & & & \\
\hline \multicolumn{8}{|l|}{ Occupation } \\
\hline Agriculturist & $32(17.1)$ & $155(82.9)$ & $187(42.6)$ & $1.20(0.72-2.01)$ & 0.490 & & \\
\hline Nonagriculturist & $37(14.7)$ & $215(85.3)$ & $252(57.4)$ & & & & \\
\hline \multicolumn{8}{|c|}{ Wearing shoes when outside } \\
\hline No & $24(17.8)$ & $111(82.2)$ & $135(30.2)$ & $1.24(0.72-2.14)$ & 0.430 & & \\
\hline Yes & $45(14.8)$ & $259(85.2)$ & $304(69.2)$ & & & & \\
\hline \multicolumn{8}{|c|}{$\begin{array}{l}\text { Wearing boots when tapping } \\
\text { rubber/gardening }\end{array}$} \\
\hline No & $27(16.1)$ & $141(83.9)$ & $168(38.3)$ & $0.96(0.57-1.62)$ & 0.873 & & \\
\hline Yes & $42(15.5)$ & $229(84.5)$ & $271(61.7)$ & & & & \\
\hline \multicolumn{8}{|c|}{ Fresh vegetable consumption } \\
\hline No & $31(16.9)$ & $152(83.1)$ & $183(41.7)$ & & & & \\
\hline Yes & $38(14.8)$ & $218(85.2)$ & $256(58.3)$ & $0.86(0.51-1.43)$ & 0.552 & & \\
\hline \multicolumn{8}{|c|}{ Washing vegetables before eating } \\
\hline No & $21(31.8)$ & $45(68.2)$ & $66(15)$ & $3.16(1.73-5.76)$ & $<0.001^{*}$ & $3.19(1.70-6.00)$ & $<0.001^{*}$ \\
\hline Yes & $48(12.9)$ & $325(87.1)$ & $373(85)$ & & & & \\
\hline \multicolumn{8}{|c|}{ Handwashing before eating } \\
\hline No & $11(16.2)$ & $57(83.8)$ & $68(15.5)$ & $1.01(0.52-2.11)$ & 0.910 & & \\
\hline Yes & $58(15.6)$ & $313(84.4)$ & $371(84.5)$ & & & & \\
\hline \multicolumn{8}{|c|}{ Handwashing after defecation } \\
\hline No & $4(26.7)$ & $11(73.3)$ & $15(3.4)$ & $2.01(0.62-6.50)$ & 0.245 & & \\
\hline Yes & $65(15.3)$ & $359(84.7)$ & $424(96.6)$ & & & & \\
\hline \multicolumn{8}{|c|}{ Handwashing after contact with soil } \\
\hline No & $6(15.4)$ & $33(84.6)$ & $39(8.9)$ & $0.97(0.39-2.42)$ & 0.952 & & \\
\hline Yes & $63(15.8)$ & $337(84.3)$ & $400(91.1)$ & & & & \\
\hline \multicolumn{8}{|c|}{ Defecating in an open field } \\
\hline No & $60(14.8)$ & $346(85.2)$ & $406(92.7)$ & $2.16(0.96-4.88)$ & 0.063 & $2.65(1.14-6.15)$ & $0.023^{*}$ \\
\hline Yes & $9(27.3)$ & $24(72.7)$ & $33(7.5)$ & & & & \\
\hline
\end{tabular}

*Statistically significant at $P<0.05$

STH infections than those who washed vegetables before eating them $(A O R=3.19 ; 95 \%$ CI 1.70-6.00). Defecation in an open field increased the risk of STH infection by 2.65 times $(\mathrm{AOR}=2.65 ; 95 \%$ CI 1.14-6.15) (Table 3 ).

\section{Discussion}

This study was conducted in Nakhon $\mathrm{Si}$ Thammarat Province, an area endemic for soil-transmitted helminthiasis according to past and present studies and reports 
[8-10]. In our study, the overall prevalence of STH infections in the elderly population was $15.7 \%$, which is consistent with the rate of intestinal parasitic infections among elderly individuals (17.7\%) in a previous study conducted in Chachoengsao Province [15]. The prevalence in this study was lower than those reported in other studies conducted in different regions of Thailand, including Chanthaburi Province (29.6\%) and Surin Province (16.2\%) [16]. In contrast, the overall prevalence in this study was higher than those in previous studies in Nakhon Si Thammarat Province (9.3\%) and Songkhla Province (5.3\%) [10, 17]. The observed discrepancy might be due to differences in the climate, geographic location, age of the study population, sampling techniques, sociodemographic features and culture.

Hookworms were the most predominant STH parasites, consistent with a previous study from China demonstrating that hookworms were the most prevalent in the elderly population [22]. In addition, the observed hookworm infection prevalence of $10.9 \%$ was higher than those in rural communities of Chachoengsao Province [15], Khon Kaen Province [23], Surin Province [16] and Songkhla Province [17]. In our study, the prevalence of hookworm infection in elderly individuals aged more than 80 years $(19 \%)$ was higher than those in individuals aged $60-69$ years $(9.1 \%)$ and $70-79$ years $(11.3 .4 \%)$. The second most predominant parasite was $S$. stercoralis, with a prevalence rate of $3.4 \%$, according to APC. Regarding the parasitological techniques for the diagnosis of S. stercoralis, APC has been recommended for epidemiologic purposes when compared with the FECT [24]. The prevalence of $S$. stercoralis in the elderly population was higher than that in a previous study conducted among adult populations in Nakhon $\mathrm{Si}$ Thammarat Province (1.0\%) using APC [10]. In addition, the lowest prevalence of STHs was $2.1 \%$ for T. trichiura, which is higher than those in previous reports conducted in central [15] and southern Thailand [10]. No A. lumbricoides was detected in this study, which was consistent with a study of schoolchildren and adults conducted in Nakhon Si Thammarat Province [8-10]. In contrast, A. lumbricoides was commonly detected in studies conducted in northern Thailand and northeastern Thailand [8, 25-27]. Differences in the prevalence may be due to several factors, including variations in examination techniques, geographical areas, age groups, levels of education, occupations, food consumption habits, and personal hygiene behaviors $[8,16,17,28]$.

In this study, almost all the people with STH infections had light-intensity infections. Only one case of moderateintensity hookworm infection was noted. These findings are consistent with previous studies in southern Thailand $[8,10]$.

Our study demonstrated a significant association between male sex and STH infection. Males had a higher prevalence of STH infections than females, consistent with previous studies in Thailand [10, 29]. We found that males were 1.85 times more likely to be infected with STHs than females. The high prevalence in males might be because males engage in outdoor activities more, making them more susceptible to STH infections than females. In the comparison of all age categories, this study showed that elderly individuals aged more than 80 years had a slightly higher prevalence of STH infections than those younger than 80 years. This result was in contrast to another study conducted among elderly individuals in Brazil that revealed that elderly individuals aged more than 80 years had a lower prevalence of STH infections than younger people [30]. However, a limited number of participants were aged older than 80 years in that study; thus, the result might not truly represent the rate of STH infections among the extremely elderly population.

Regarding behavioral risk factors, logistic regression analyses revealed that consuming unwashed fresh vegetables and defecation in an open field were significantly associated with STH infection. Elderly individuals who did not regularly practice vegetable washing were 3.19 times more likely to be infected with STHs than those who did wash vegetables. Several studies have reported that consuming unwashed fresh vegetables is a risk factor for STH infection [31, 32]. Recently, contamination by $\mathrm{STH}$ parasites has been reported in fresh vegetables from southern Thailand, with a contamination rate of $35.1 \%$ [32]. Therefore, the participants who lived in this area might have possibly acquired STH infections from ingesting STH-contaminated fresh vegetables $[32,33]$. This study found that elderly individuals who defecated in an open field had a 2.65 times increased risk of STH infection. Unhygienic defecation habits are associated with a high risk of STH infection, especially infection by S. stercoralis, and hookworms that live in soil can be directly transmitted from the soil to humans through skin penetration by filariform larvae (the infectious stage) $[34,35]$. Moreover, open defecation can cause dispersion of STHs as well [36]. This study found that other factors such as age, educational level, monthly household income, consumption of partially-cooked food, handwashing before eating and occupation were not significantly associated with STH infection, consistent with previous studies in Thailand $[10,15]$.

The results of this study confirmed that STH infections are not only limited to children and adults in the study area $[9,10]$ but are also prevalent among elderly individuals. We suggest that health education and deworming programs should also be implemented among elderly individuals who may undermine the progress of control activities by serving as sources of infections to children and other family members. 
The study limitations are as follows. In this study, we obtained only a single stool specimen from each participant, which might underestimate the presence of parasites, as the standard specimen collection protocol is three specimens with intervals of 3 days. Another limitation of this study was the lack of information on clinical symptoms. We did not gather data on underlying medical conditions or the immune status of the participants, which might be possible confounders for STH infection. Furthermore, this study was limited to only elderly individuals in a region of southern Thailand. Additional studies should be performed in urban or rural areas and in different parts of the country.

\section{Conclusions}

The findings suggested that STH infection is prevalent, and that hookworms are the most common STH species among elderly populations in southern Thailand. Male sex, consumption of unwashed fresh vegetables, and defecation in an open field increased the risk of STH infections. Health education and deworming programs should be implemented among the elderly population to improve health as well as household sanitation.

\section{Abbreviations}

STH: Soil-transmitted helminth; EPG: Eggs per gram; AOR: Adjusted odds ratio; Cl: Confidence interval; IQR: Interquartile range; COR: Crude odds ratio; WHO: World Health Organization

\section{Acknowledgments}

The authors thank the study participants for their participation and village health volunteers in Thai Buri, Tha Sala, Hua Tapan, Mokhalan, and Pho Thong subdistricts for their assistance with this survey. The authors also thank Miss Hatairat Hongphruk for her assistance in preparing the reagents and laboratory instruments.

\section{Authors' contributions}

RK, NP and CP conceived and designed the study. RK, NP and CP collected the data. RK, PV and CP performed the experiments. RK, NP and CP analyzed the data. RK and CP drafted the manuscript, and NP and PV revised the manuscript. All authors read and approved the final manuscript.

\section{Funding}

This research was partially supported by the New Strategic Research (P2P) project, Walailak University, Thailand. The funder played no role in the study design, data collection, and data analysis and interpretation.

\section{Availability of data and materials}

All data generated or analyzed during this study are included within the published article.

\section{Ethics approval and consent to participate}

The study protocol was submitted to and approved by the Ethics Committee of Walailak University (approval number: WUEC-19-033-01). All the study participants were informed of the purpose of the study and their right to refuse participation. Written informed consent was obtained prior to the interview and sample collection. Elderly individuals infected with hookworms, S. stercoralis and T. trichiura, were treated with the recommended dosage of albendazole for each parasite.

\section{Consent for publication}

Not applicable.

\section{Competing interests}

The authors declare that they have no competing interests.

\section{Author details}

${ }^{1}$ School of Medicine, Walailak University, Nakhon Si Thammarat, Thailand. ${ }^{2}$ Tropical Medicine Research Unit, Research Institute for Health Sciences, Walailak University, Nakhon Si Thammarat 80160, Thailand. ${ }^{3}$ Department of Tropical Pathology, Faculty of Tropical Medicine, Mahidol University, Bangkok, Thailand.

Received: 6 April 2020 Accepted: 29 November 2020

Published online: 07 December 2020

\section{References}

1. Bethony J, Brooker S, Albonico M, Geiger S, Loukas A, Diemert D, et al. Soiltransmitted Helminth infections: Ascariasis, Trichuriasis, and hookworm. Lancet. 2006;367:1521-32.

2. Silva N, Brooker S, Hotez P, Montresor A, Engels D, Savioli L. Soil-transmitted Helminth infections: updating the global picture. Trends Parasitol. 2004;19: $547-51$.

3. Hotez P, Molyneux D, Fenwick A, Kumaresan J, Sachs S, Sachs J, et al. Control of neglected tropical diseases. N Engl J Med. 2007;357:1018-27.

4. WHO. Soil-transmitted helminth infections. 2019. https:/www.who.int/newsroom/fact-sheets/detail/soil-transmitted-helminth-infections. Accessed 21 May 2019.

5. Pullan RL, Smith JL, Jasrasaria R, Brooker SJ. Global numbers of infection and disease burden of soil transmitted helminth infections in 2010. Parasit Vectors. 2014;7(1):37.

6. Dunn JC, Turner HC, Tun A, Anderson RM. Epidemiological surveys of, and research on, soil-transmitted helminths in Southeast Asia: a systematic review. Parasit Vectors. 2016;9(1):31.

7. Strunz EC, Addiss DG, Stocks ME, Ogden S, Utzinger J, Freeman MC. Water, sanitation, hygiene, and soil-transmitted helminth infection: a systematic review and meta-analysis. PLoS Med. 2014;11(3):e1001620.

8. Wongsaroj T, Nithikathkul C, Rojkitikul W, Nakai W, Royal L, Rammasut P. National survey of helminthiasis in Thailand. Asian biomed. 2014;8(6):779.

9. Punsawad C, Phasuk N, Bunratsami S, Thongtup K, Viriyavejakul P, Palipoch $S$, et al. Prevalence of intestinal parasitic infections and associated risk factors for hookworm infections among primary schoolchildren in rural areas of Nakhon Si Thammarat, southern Thailand. BMC Public Health. 2018; 18(1):1118.

10. Punsawad C, Phasuk N, Bunratsami S, Thongtup K, Siripakonuaong N, Nongnaul S. Prevalence of intestinal parasitic infection and associated risk factors among village health volunteers in rural communities of southern Thailand. BMC Public Health. 2017;17(1):564.

11. Anantaphruti M, Waikagul J, Maipanich W, Nuamtanong S, Watthanakulpanich D, Pubampen S, et al. School-based health education for the control of soil-transmitted helminthiases in Kanchanaburi province, Thailand. Ann Trop Med Parasitol. 2008;102(6):521-8.

12. Tun A, Myat SM, Gabrielli AF, Montresor A. Control of soil-transmitted helminthiasis in M yanmar: results of 7 years of deworming. Tropical Med Int Health. 2013;18(8):1017-20.

13. Al-Delaimy AK, Al-Mekhlafi HM, Nasr NA, Sady H, Atroosh WM, Nashiry M, et al. Epidemiology of intestinal Polyparasitism among orang Asli school children in rural Malaysia. PLoS Negl Trop Dis. 2014;8(8):e3074.

14. National Statistical Office, Ministry of Information and Communication Technology Thailand. Demographic, population, and housing statistic. 2012. http://www.nso.go.th/sites/2014en. Accessed 21 May 2019.

15. Suntaravitun $P$, Dokmaikaw A. Prevalence of intestinal parasites and associated risk factors for infection among rural communities of Chachoengsao Province, Thailand. Korean J Parasitol. 2018;56(1):33-9.

16. Rattanapitoon S, Rujirakul R, Ueng-arporn N, Matrakool L, Namwichaisiriku N, Churproong S, et al. Community-based cross-sectional study of carcinogenic human liver fluke in elderly from Surin Province, Thailand. Asian Pac J Cancer Prev. 2012;13:4285-8.

17. Kitvatanachai S, Taylor A, Rhongbutsri P, Taylor WRJ. Modified Harada-Mori and simple wet mount to determine hookworm infections in Yo Island urban area, Songkhla, Southern Thailand. Trop Med Health. 2019;47(1):27.

18. Yamane T. Statistics, an introductory analysis. 2nd ed. New York: Harper and Row; 1967.

19. CDC. Laboratory identification of parasitic diseases of public health concern. 2019. https://www.cdc.gov/dpdx/diagnosticprocedures/stool/index.html. Accessed 21 May 2019. 
20. WHO. Guideline: preventive chemotherapy to control soil-transmitted helminth infections in at-risk population groups. 2017. https://apps.who.int/iris/ bitstream/handle/ 10665/258983/9789241550116-eng.pdf?sequence=1. Accessed 3 Jun 2019.

21. Koga K, Kasuya S, Khamboonruang C, Sukhavat K, leda M, Takatsuka N, et al. A modified agar plate method for detection of Strongyloides stercoralis. Am J Trop Med Hyg. 1991;45(4):518-21.

22. Bethony J, Chen J, Lin S, Xiao S, Zhan B, Li S, et al. Emerging patterns of hookworm infection: influence of aging on the intensity of Necator infection in Hainan Province, People's Republic of China. Clin Infect Dis. 2002;35(11):1336-44.

23. Boonjaraspinyo S, Boonmars T, Kaewsamut B, Ekobol N, Laummaunwai P, Aukkanimart R, et al. A cross-sectional study on intestinal parasitic infections in rural communities, Northeast Thailand. Korean J Parasitol. 2013;51:727-34.

24. Intapan P, Maleewong W, Wongsaroj T, Singthong S, Morakote N. Comparison of the quantitative formalin ethyl acetate concentration technique and agar plate culture for diagnosis of human Strongyloidiasis. J Clin Microbiol. 2005;43:1932-3.

25. Yang $D$, Yang $Y$, Wang $Y$, Yang $Y$, Dong $S$, Chen $Y$, et al. Prevalence and risk factors of Ascaris lumbricoides, Trichuris trichiura and Cryptosporidium infections in elementary school children in southwestern China: a schoolbased cross-sectional study. Int J Environ Res Public Health. 2018;15(9):1809.

26. Shumbej T, Belay T, Mekonnen Z, Tefera T, Zemene E. Soil-transmitted helminths and associated factors among pre-school children in Butajira Town, South-Central Ethiopia: a community-based cross-sectional study. PLoS One. 2015;10(8):e0136342.

27. Yanola J, Nachaiwieng W, Duangmano S, Prasannarong $M$, Somboon $P$, Pornprasert S. Current prevalence of intestinal parasitic infections and their impact on hematological and nutritional status among Karen hill tribe children in Omkoi District, Chiang Mai Province, Thailand. Acta Trop. 2018;180:1-6.

28. Kitvatanachai S, Rhongbutsri P. Using mini Parasep襆 SF to determine intestinal parasitic infections comparing to conventional methods in gardener of Chanthaburi Province, Thailand. Asian Pac J Trop Dis. 2017;7: 596-600.

29. Laoraksawong P, Sanpool O, Rodpai R, Thanchomnang T, Kanarkard W, Maleewong W, et al. Current high prevalences of Strongyloides stercoralis and Opisthorchis viverrini infections in rural communities in Northeast Thailand and associated risk factors. BMC Public Health. 2018;18(1):940

30. Engroff P, Ely L, Silva A, Viegas K, Loureiro F, Gomes I, et al. Prevalence of intestinal parasites in the elderly enrolled in the family health strategy in Porto Alegre, Brazil. Geriatr Gerontol Aging. 2016;10:132-9.

31. Yusof AM, Mohammad M, Abdullahi MA, Mohamed Z, Zakaria R, Wahab RA. Occurrence of intestinal parasitic contamination in select consumed local raw vegetables and fruits in Kuantan, Pahang. Trop Life Sci Res. 2017;28(1):23

32. Punsawad C, Phasuk N, Thongtup K, Nagavirochana S, Viriyavejakul P. Prevalence of parasitic contamination of raw vegetables in Nakhon $\mathrm{Si}$ Thammarat province, southern Thailand. BMC Public Health. 2019;19(1):34.

33. Berger C, Sodha S, Shaw R, Griffin P, Pink D, Hand P, et al. Fresh fruit and vegetables as vehicles for the transmission of human pathogens: fresh produce as vehicles for transmission of human pathogens. Environ Microbiol. 2010;12:2385-97.

34. CDC. Hookworm. 2013. https://www.cdc.gov/parasites/hookworm/biology. html. Accessed 3 Jun 2019.

35. Schär F, Trostdorf U, Giardina F, Khieu V, Muth S, Marti H, et al. Strongyloides stercoralis: global distribution and risk factors. PLoS Negl Trop Dis. 2013;7(7):e2288.

36. Schmidlin T, Hürlimann E, Silué KD, Yapi RB, Houngbedji C, Kouadio BA, et al. Effects of hygiene and defecation behavior on helminths and intestinal protozoa infections in Taabo, Côte d'Ivoire. PLoS One. 2013; 8(6):e65722.

\section{Publisher's Note}

Springer Nature remains neutral with regard to jurisdictional claims in published maps and institutional affiliations.

\section{Ready to submit your research? Choose BMC and benefit from}

- fast, convenient online submission

- thorough peer review by experienced researchers in your field

- rapid publication on acceptance

- support for research data, including large and complex data types

- gold Open Access which fosters wider collaboration and increased citations

- maximum visibility for your research: over $100 \mathrm{M}$ website views per year

At BMC, research is always in progress.

Learn more biomedcentral.com/submissions 